\title{
REVIEW
}

\section{The significance of stem cells in free-living flatworms: one common source for all cells in the adult}

\author{
Roland Peter ${ }^{1}$, Robert Gschwentner ${ }^{2}$, Wolfgang Schürmann ${ }^{1}$, Reinhard M. Rieger ${ }^{2}$, Peter Ladurner ${ }^{2}$ \\ ${ }^{1}$ Department of Genetics and General Biology, University of Salzburg, Salzburg, Austria \\ ${ }^{2}$ Department of Zoology and Limnology, University of Innsbruck, Innsbruck, Austria
}

Received $24^{\text {th }}$ October 2003.

Published online $30^{\text {th }}$ October 2003.

\begin{abstract}
Summary
A survey of the current knowledge on stem cells and cell proliferation in turbellarians is presented, with special focus on recent results obtained by the authors when studying cell kinetics and cultivating neoblasts from various species. Differentiated somatic cells do not divide in flatworms. In these animals neoblasts constitute a proliferative compartment. These cells are rather uniform when viewed through a light microscope, but constitute a heterogeneous population comprising actual stem cells, progenitors and early differentiation stages. Cell kinetics were monitored by the incorporation of 5-bromo-2' -deoxyuridine and by immunocytochemical staining for mitoses in the marine microturbellarians Macrostomum, Microstomum and Convolutriloba. Distribution patterns of proliferating cells within the body were documented, and a tentative interpretation of the differences observed is given. Correlations to the nervous system and the mode of reproduction seem to exist. To analyse neoblasts quantitatively and establish primary cultures, neoblasts from the freshwater planarians (triclads) Dugesia and Schmidtea were isolated, purified and subjected to various culture conditions, with the ultimate but not yet achieved goal of establishing a permanent stem cell line. The role of stem cells in flatworms is compared with the situation in mammals, with special focus on embryogenesis, germline and strategies of cell renewal.
\end{abstract}

Keywords: BrdU labelling - cell cultures - cell proliferation - neoblasts - germline - stem cells

\section{INTRODUCTION}

Flatworms (Platyhelminthes) renew all their tissues from a common population of stem cells belonging to a proliferative compartment of somatic cells that is opposed to a functional compartment of differentiated cells without the ability to divide (Baguñà 1998). This view has been derived from the observation that the only somatic cells capable of mitosis are neoblasts, a population of cells comprising stem cells. The outlined strategy contrasts to the situation observed in other animal taxa and familiar from human physiology where there is a multiplicity of both proliferating differentiated cells and stem cells specific for and located in various tissues. Most cell biological studies on platyhelminths have dealt with free-living flatworms (turbellarians). There are, however, similar observations in the parasitic taxa (see, for example, Gustafsson 1990, Wikgren and Knuts 1970) and strong indications that the same stem cell strategy is valid throughout the platyhelminths (Ehlers 1985). Reviews on neoblasts, their interrelationships to other cells and on theories of regeneration and cell renewal in turbellarians were presented by Baguñà et al. (1994), Gremigni (1988) 
and Peter (2001) among others. This paper refers especially to some selected species of turbellarians whose cell biology has been studied in more detail. They cover a wide range of phylogenetic relationships: Whereas planarians occupy a position in the animal dendrogram not far from the parasitic plathyhelminths (e.g. cestodes and trematodes), most authors place the Acoelomorpha near the origin of platyhelminths and the platyhelminths as a whole near the origin of the "Bilateria". This huge taxon unites the animals with bilateral body symmetry, including the vertebrates.

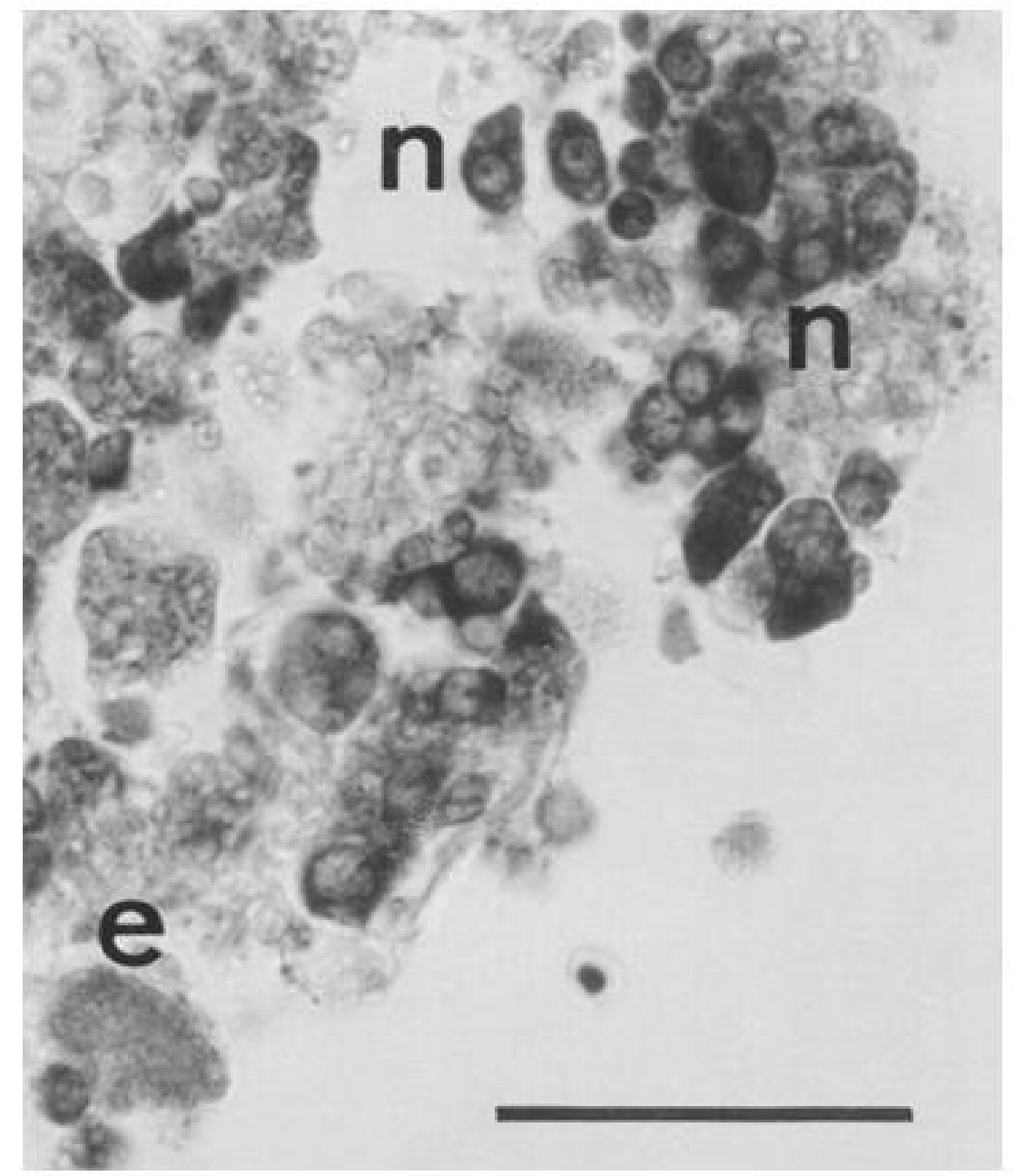

Fig. 1. Neoblasts in a histological section through the wound region of Schmidtea polychroa stained with azure A eosin B. The wound was kept open by the relaxing agent magnesium chloride $(21 \mathrm{mM})$, and a great number of neoblasts (n) accumulated there. The narrow cytoplasmic rims and the nucleoli (both dark in the figure) were stained intensely blue; e = epithelial cell. Scale bar $50 \mu \mathrm{m}$.

The concept of a totipotent stem cell that was thought to be identical with a cell type nowadays mostly termed "neoblast" was originally developed on the basis of histological studies of the regeneration process in planarians (triclad turbellarians), where small cells with a high nucleocytoplasmic ratio and a strongly basophilic cytoplasm are scattered throughout the parenchyma and build up the regeneration blastema where they differentiate to reconstruct the missing tissues. A survey of the alternative terms for neoblasts is given by Brøndsted (1969). The term stem cells ("Stammzellen") was already coined for these cells by Keller (1894). The common proliferative pool unites somatic and germ cells, implying the fact that flatworms lack a separate germline (Peter 2002). One cell pool gives rise to both sexual and asexual reproduction (Peter et al. 2001). 


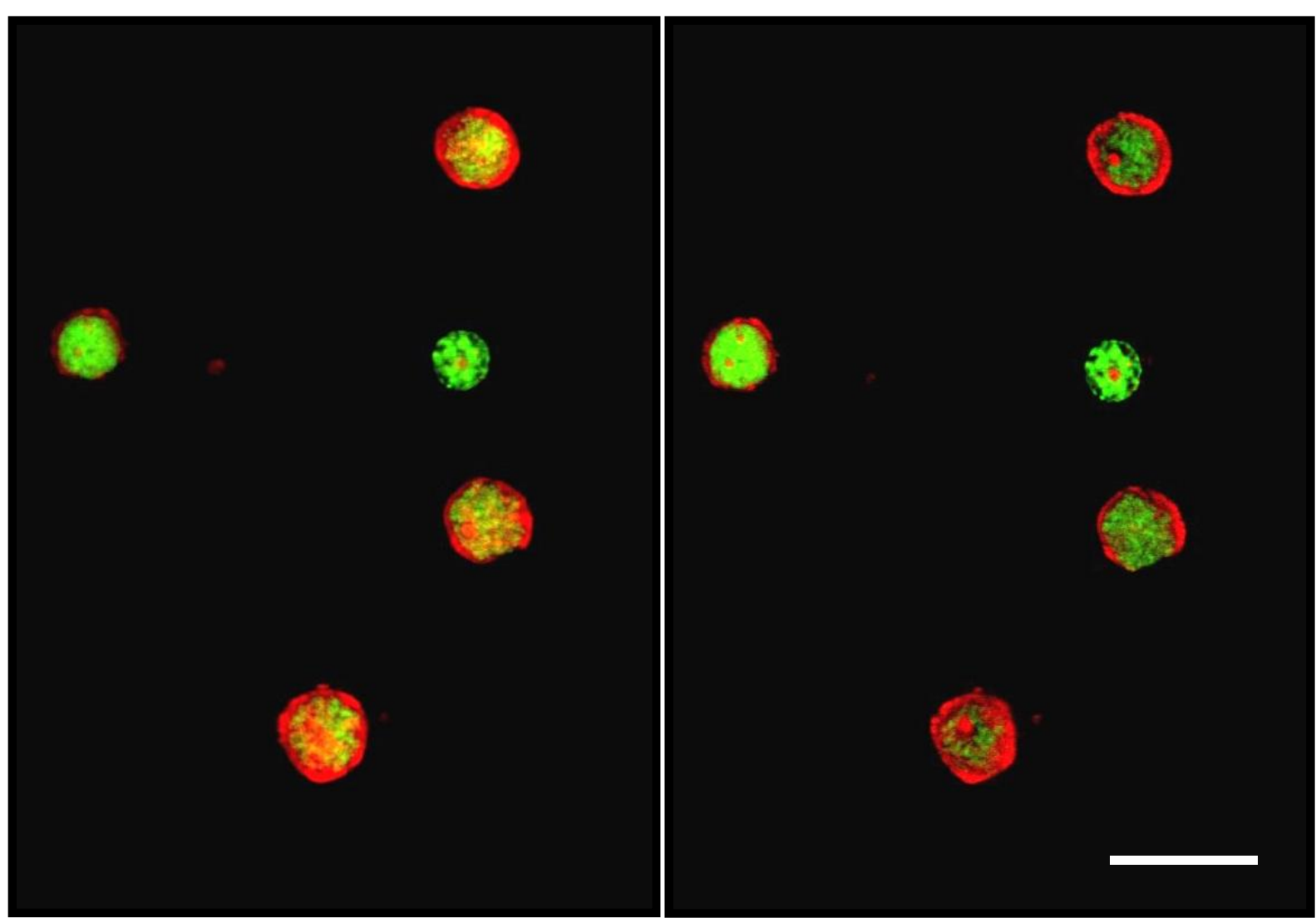

Fig. 2. Neoblasts from Dugesia tahitiensis stained for DNA (green) and RNA (red) with the fluorescent dye acridine orange and spun down to a slide in a cytorotor (Heraeus Megafuge). The prominent nucleoli (1-3 per cell) contrast to the nuclear DNA (green) by the same intense red phosphorescence as the cytoplasm. Two optical sections taken at a distance of $1.30 \mu \mathrm{m}$ are shown. Laser scanning microscope Zeiss LSM 510 Meta; excitation: $458 \mathrm{~nm}$ (for RNA) and $488 \mathrm{~nm}$ (for DNA), emission filters: LP $650 \mathrm{~nm}$ and BP 505-550 nm. Confocal image by K. Pusitz, Carl Zeiss Ges. m. b. H., Vienna. Scale bar $20 \mu \mathrm{m}$.

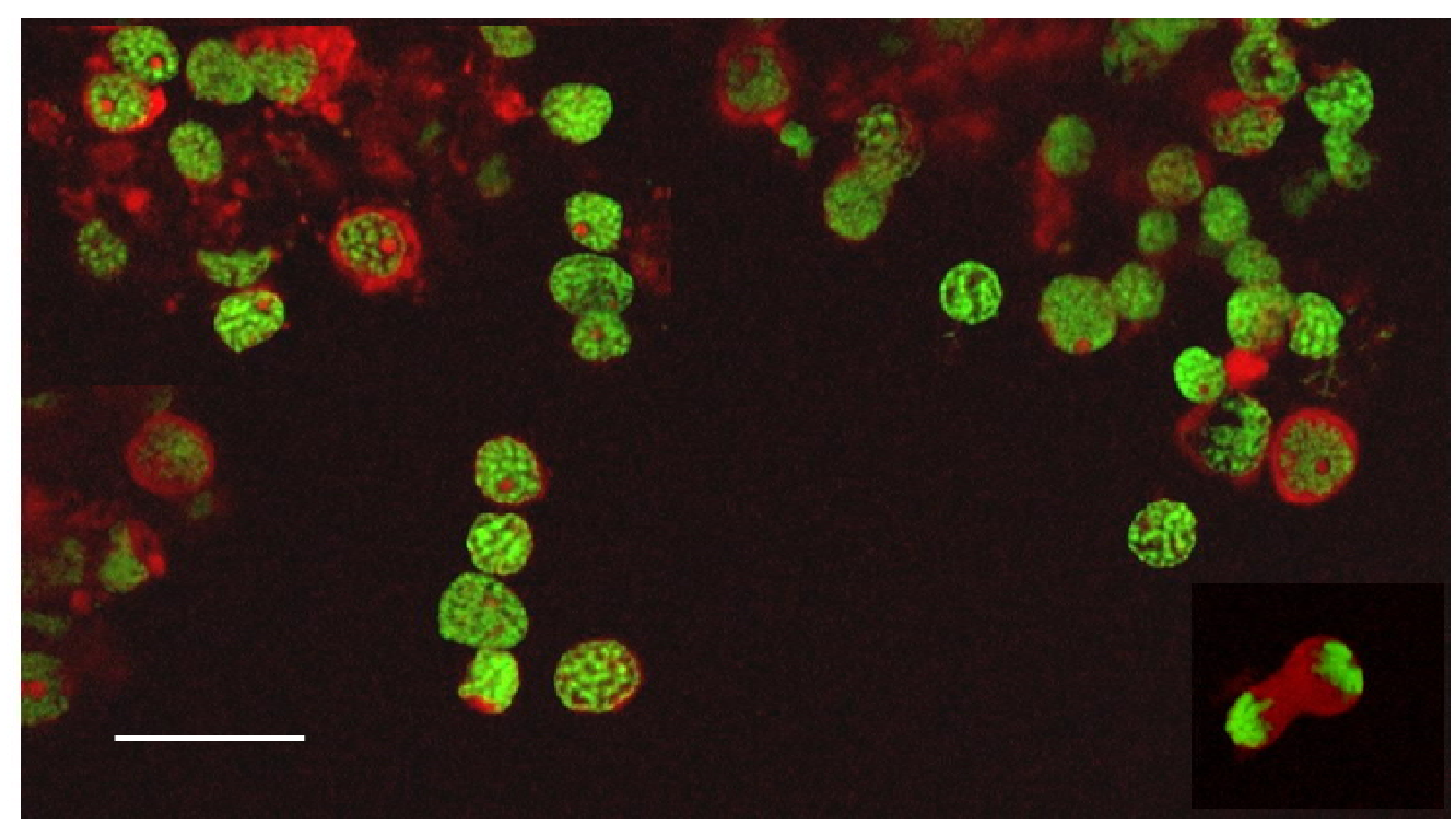

Fig. 3. Enriched neoblast preparation with an anaphase, obtained from Dugesia tahitiensis by mechanical tissue disintegration and density gradient centrifugation. Fluorescent staining with acridine orange. Technical details as for Fig. 2. Confocal image (LSM 510 Meta) by K. Pusitz, Carl Zeiss Ges. m. b. H., Vienna. Scale bar $20 \mu \mathrm{m}$. 


\section{NEOBLASTS: COMMON TRAITS AND A HIDDEN DIVERSITY}

Neoblasts are defined by their strongly basophilic cytoplasm rich in ribosomes, with some mitochondria, but lacking any further organelles except the nucleus that contains one to three prominent nucleoli. Classical staining methods have been azure $\mathrm{A}$ - eosin B (Pedersen 1959) and methyl green - pyronin (Pedersen 1958), both relying on the basophily of the cytoplasm. In tissue sections, neoblasts appear spindle-shaped or pear-shaped to ovoid (Fig. 1).

Staining with the fluorescent dye acridine orange was recently adapted for isolated neoblasts, offering the possibility to quantify DNA and RNA contents by video microscopy and image analysis (Behensky et al. 2001). In this way DNA and RNA profiles can be obtained and used to characterize the neoblast population of a turbellarian and to monitor its changes during a physiological process or experimental treatment, like gamma irradiation (Buchner and Peter 2002). Such studies revealed dose-dependent differences between neoblast populations in Dugesia tahitiensis. It is, however, too early to decide how far these referred to developmental stages of one cell type or to several subtypes. Confocal microscopy detects additional details of RNA and DNA distribution within a cell and promises to throw still more light on the heterogeneity of neoblasts (Fig. 2).

Such a heterogeneity has long been deduced from experimental observations and ultrastructural studies. Cell kinetic data with hydroxyurea treatment indicated at least two different cell cycle periods for freshwater planarians (Saló and Baguñà 1984). These results were recently doubted by Newmark and Sánchez Alvarado (2000) who used the incorporation of 5-bromo-2'-deoxyuridine (BrdU) to study cell proliferation in planarians (triclads). On the other hand, ${ }^{3} \mathrm{H}$-thymidine incorporation into microturbellarians did suggest different cell cycle periods (Palmberg 1990). These results were confirmed by BrdU incorporation into Macrostomum (Ladurner et al. 1998, 2000). Results obtained with BrdU labelling for light and electron microscopy support the existence of three spatially separate subpopulations of proliferating cells in this genus: somatic neoblasts ("mesodermal" and gastrodermal) and gonadal stem cells. There is evidence that all these might be derived from a single neoblast stem cell pool (see reviews in Peter 2001 and Peter et al. 2001). The behaviour of isolated neoblasts from the planarian
Schmidtea polychroa in density gradient centrifugation was an additional indication of differences within the proliferative cell pool; in this connection, it was possible to discern four tentative subtypes (Schürmann et al. 1998).

Ultrastructural studies detected differences in neoblasts in several cases. Probably the first report on this topic was given by Sauzin-Monnot (1973) who described sequential stages in the development of a neoblast to a differentiated cell: The increase in polysomes and the beginning formation of the endoplasmic reticulum are followed by the appearance of Golgi vesicles. Then complete Golgi structures form, and the cytoskeleton increases, beginning with the growth of microtubules. The changes observed thereafter depend on the cell type emerging from the neoblast.

Chromatoid bodies are typical for planarians but were not yet found in other turbellarians. These emissions from the nucleus were found to contain RNA and to disappeare progressively when neoblasts enter differentiation (Auladell et al. 1993, Morita and Best 1984). Relationships of these structures to vasa-genes specifically expressed in germline cells and totipotent somatic stem cells have been discovered (Shibata et al. 1999). In Macrostomum three types or stages of neoblasts could be distinguished, based on their nuclear morphology (Rieger et al. 1999).

In addition to the reports cited above, the current view of stem cells strongly demands the existence of more than one type of proliferating cells. If the general model of stem cell strategies applies to turbellarians, this implies that there are several types of neoblasts. A succession from self-renewing stem cells, forming a population persisting at least for the life time of the individual, to several generations of progenitor cells with progressive commitment and restricted proliferative potential, eventually leading to terminally differentiated cells, has been found in the systems that have been studied most thoroughly. Such a succession is generally thought to be characteristic for stem cell strategies (Loeffler and Roeder 2002, Morrison et al. 1997, Weissman 2000). Obviously, neoblasts must comprise all these cell types, the system as a whole being totipotent, but at the same time a black box. Presently we are still missing the possibility of discriminating between these types of proliferating neoblasts. Therefore the question if totipotency holds true for a single cell type or applies to the proliferative compartment as a whole is still left open (for a detailed discussion see Peter 2001). 


\section{ANALYSING THE PROLIFERATIVE COMPARTMENT: THE IN VITRO APPROACH}

The cultivation of neoblasts isolated from living animals should offer possibilities of studying their proliferation and differentiation potentials in vitro and in vivo. Various attempts have been made to isolate and cultivate these cells from planarians (for review see Schürmann and Peter 2001). A relatively simple method uses hypotonic treatment of planarian fragments to select neoblasts that survive, while other cell types degenerate within some days
(Betchaku 1967). Presently the most refined technique uses mechanical tissue disintegration in a Dounce homogenizer with a loosely fitting pestle, followed by centrifugation in Percoll density gradients and cultivation in a medium isotonic to the planarian body (Schürmann and Peter 2001, Schürmann et al. 1998). Considerable progress has been made since then. The asexual species Dugesia tahitiensis proved to be an excellent source of neoblasts (Fig. 3). Various coatings of culture dishes (rat collagens I and IV, supernatants of planarian tissue disintegrations) were tried.

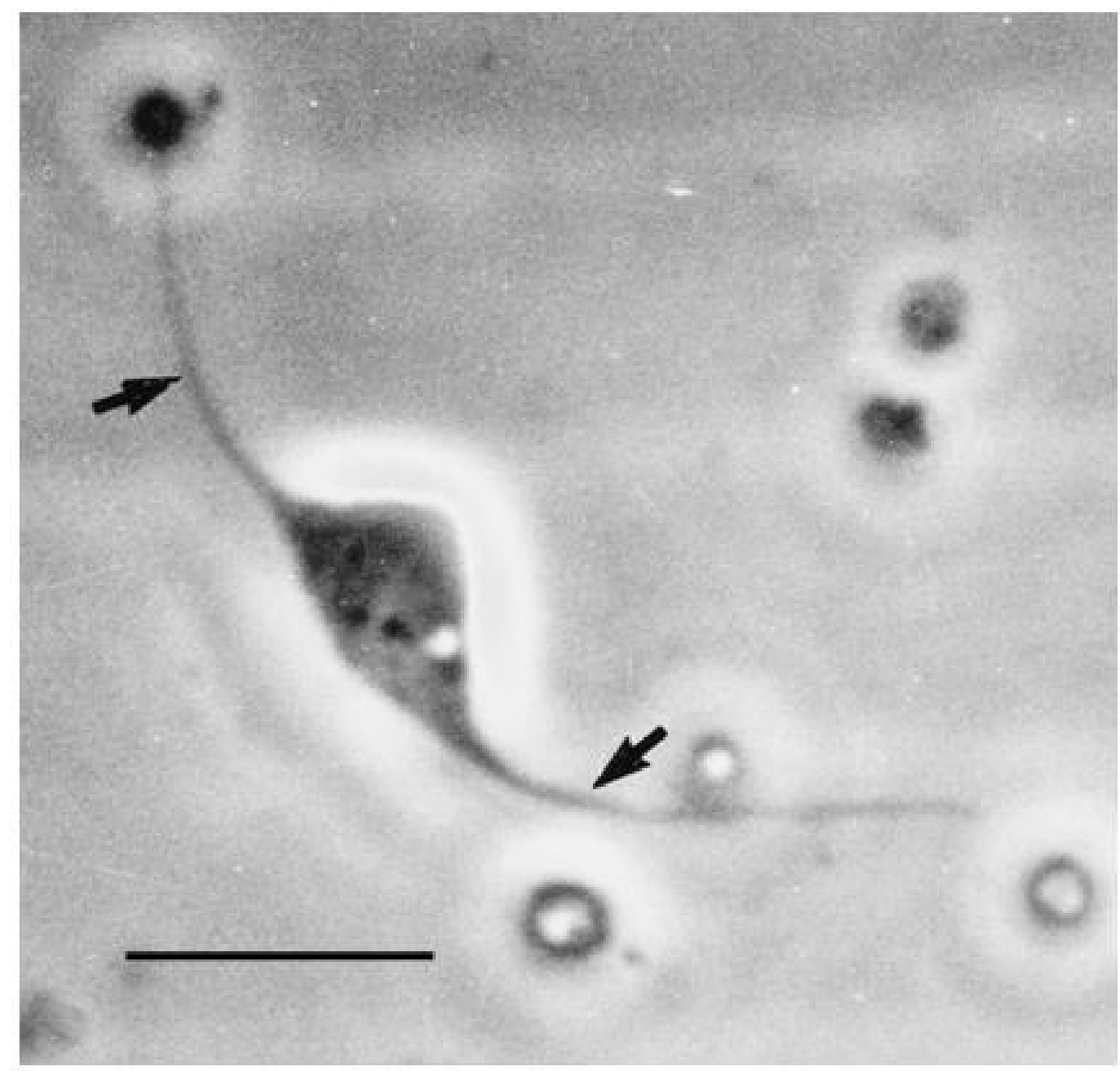

Fig. 4. Neoblast from Schmidtea polychroa with processes (arrows) developed after having been cultivated for 46 hours in the hyposmotic medium "5/8-concentrated Holtfreter's solution" [80 mOsmol / kg; see Betchaku (1967)] that had been supplemented with $3 \%$ foetal bovine serum proteins. Scale bar $20 \mu \mathrm{m}$.

Significant, but temporary changes in cytomorphology could be observed in such cultures. Transitory processes (Fig. 4) appeared in a fraction of cultivated neoblasts under two conditions: (1) hypotonic media with the addition of bovine serum proteins, but without a layer of extracellular matrix components and (2) isotonic media on coatings made of rat collagen I or IV, without proteins added to the medium. Most cells retained their spherical form. Neoblasts did not divide in pure cultures. Primary cultures stimulated with differentiated feeder cells from planarians showed mitoses for up 
to seven days. The addition of foetal bovine serum enhanced this effect (Schürmann and Peter 2003). However, no permanent cell line has yet been established. In previous studies, less pure neoblast suspensions from Dugesia mediterranea were injected into X-irradiated hosts of the same species and were found to repopulate these specimens (Baguñà et al. 1989). We obtained similar preparations of neoblasts from Macrostomum. They have not yet been cultivated, but are at hand for microinjection experiments with gamma-irradiated hosts.
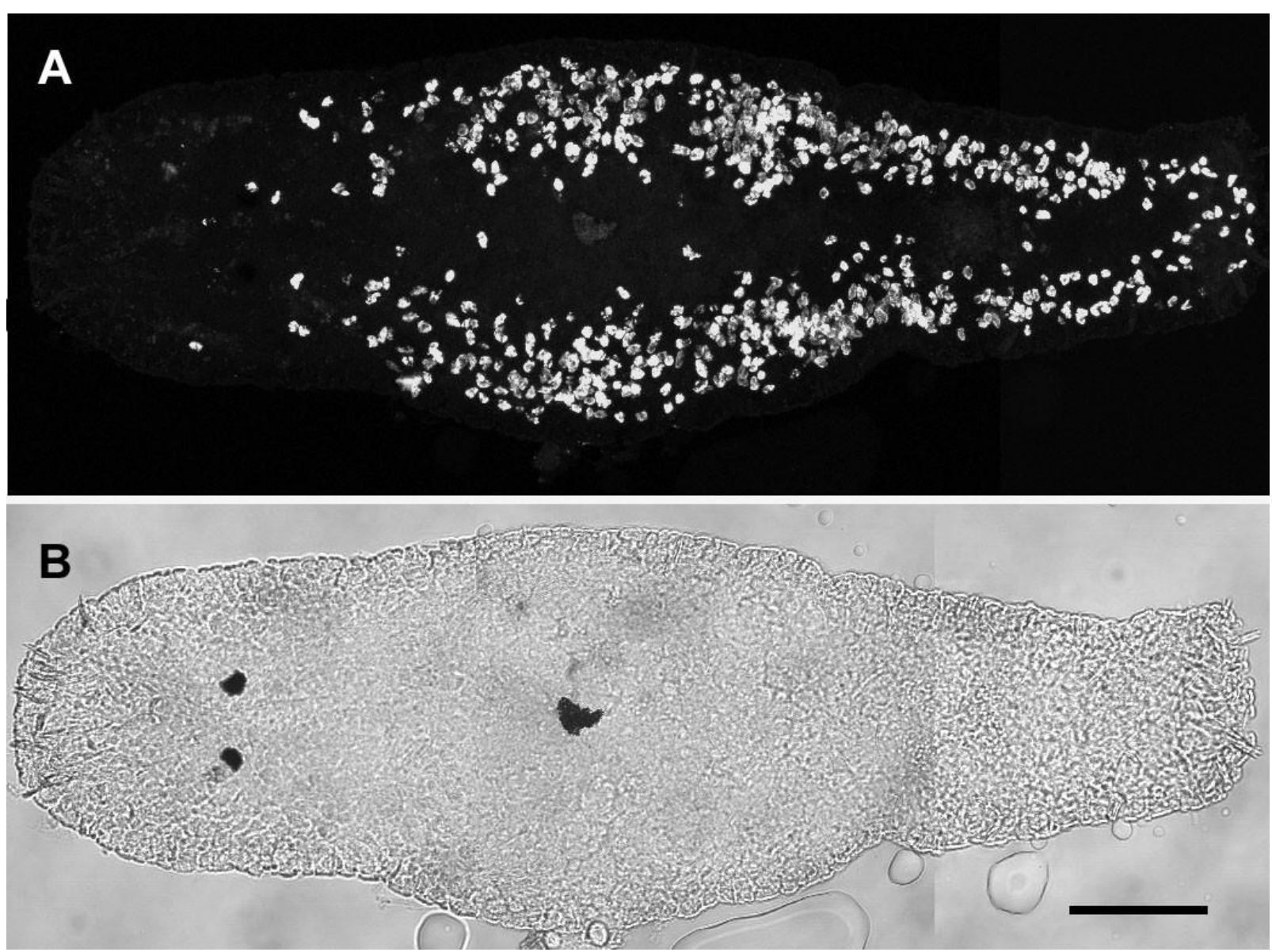

Fig. 5. Distribution of neoblasts in S-phase in Macrostomum sp. Dorsal view of a juvenile specimen. (A) Laser scanning micrograph (Zeiss LSM 510) of BrdU labelled S-phase neoblasts that show bright fluorescence against the dark background. They are arranged predominantly in two lateral bands along the nerve cords. No S-phase cells may be seen in the region in front of the eye spots; few labelled cells are located in the middle and posterior body regions. The specimen was fixed immediately after a pulse of $30 \mathrm{~min}$. (B) Nomarski interference-contrast micrograph of the same animal. Note the two eye spots near the anterior end. Scale bar $50 \mu \mathrm{m}$.

\section{ANALYSING THE PROLIFERATIVE COMPARTMENT: THE WHOLE ANIMAL APPROACH}

A lot of data exists on the distribution of neoblasts within the planarian body, and has been extensively reviewed by Brøndsted (1969). In general, there is a decrease in neoblast density from the central body portion to the most anterior and posterior regions, with particularly few neoblasts in the pharynx region and a maximum between pharynx and head. Preliminary observations on histological sections of
Dugesia tahitiensis indicate a rather homogeneous distribution, excepting the anterior end and with a minimum in the pharynx region. This distribution might be related to the asexual reproduction by transversal fission. It is however known from other species that neither the total number of neoblasts nor their distribution within the body is causally related to the regenerative potential. A more significant statement will be possible when still more patterns of cell proliferation (see below) will have been analyzed. 

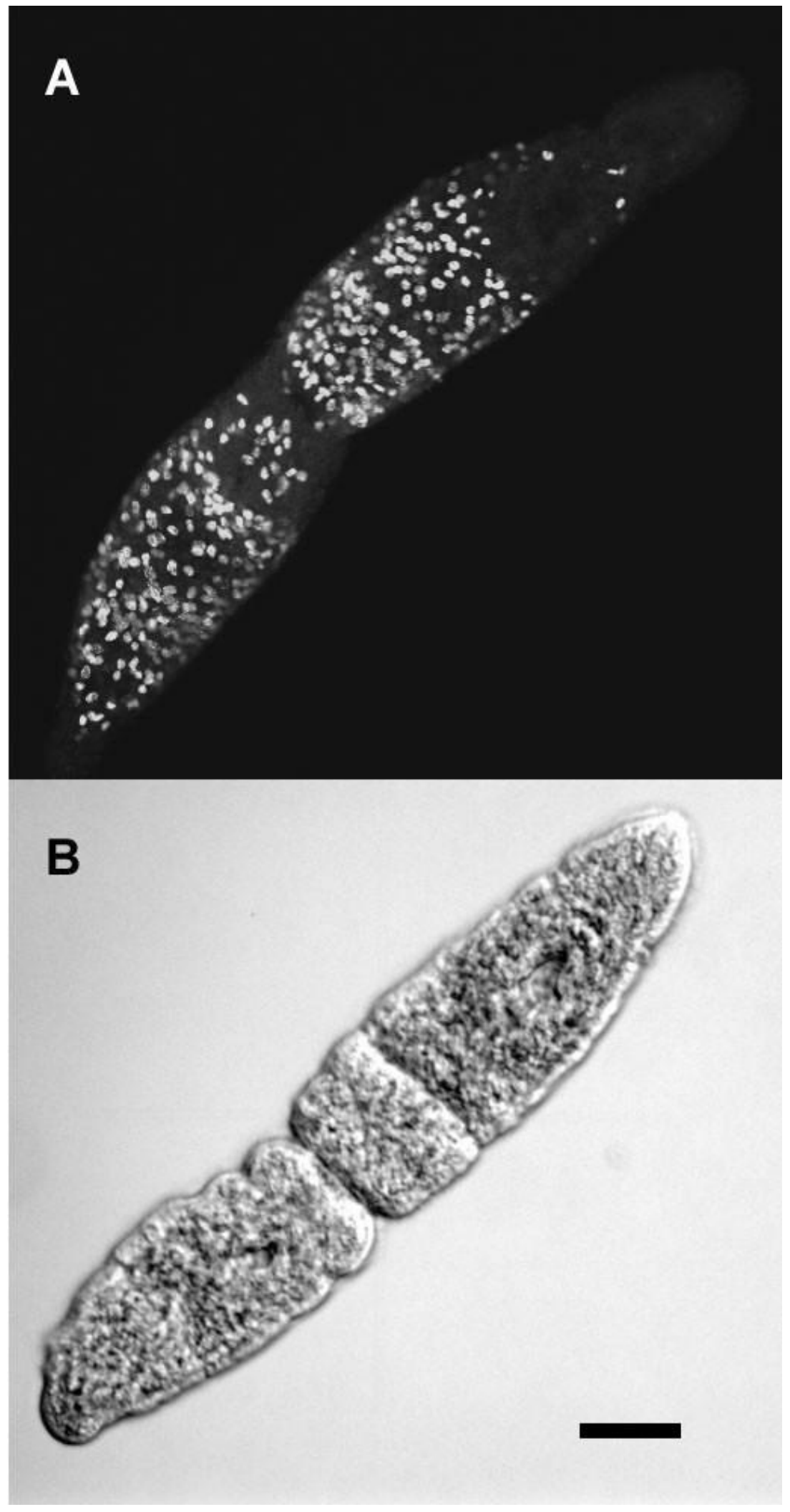

Fig. 6. Distribution of neoblasts in S-phase in Microstomum sp. (ventral view, anterior end at top right). (A) Laser scanning micrograph (Zeiss LSM 510) of S-phase neoblasts labelled by a 30 min pulse of BrdU. The specimen was fixed immediately after the pulse. Labelled cells (bright fluorescence) are arranged in a pattern that appears to correlate with the prospective fission planes: S-phase cells are completely missing or less numerous in the respective regions (confer Fig. 6B). Such a pattern is not found in all species of this genus. (B) Interference-contrast image of another animal. The prospective fission planes may be identified by lateral indentations and dark bands. Scale bar $100 \mu \mathrm{m}$. 
Totipotency of a stem cell system common to all tissues persists throughout embryonal (?) and adult life.

Additional ways of cell renewal, like transdifferentiation, cannot yet be excluded.

One proliferative compartment. No subdivisions have been described until now.

No germline. Somatic and germ cells connected throughout life by proliferative compartment.

Possibly original system for cell renewal inherited from the latest ancestor common to all Bilateria.
Totipotent stem cell system in the embryo.
Remarkable potential of transdifferentiation (?) and possibly presence of totipotent stem cells even in the adult.

Several stem cell systems (uni- and pluripotent) in addition to the division of differentiated cells.

Germline separate from somatic cell generations, with a connection only in the embryo.
Highly evolved strategies for cell renewal; possibly ancient stem cell system in addition.
Proliferation of neoblasts was monitored by the incorporation of ${ }^{3} \mathrm{H}$-thymidine in several marine microturbellarians (see for example Palmberg 1990). In this way it was proven that differentiated cells are derived from neoblasts. Still more conclusions can be drawn from BrdU incorporation studies followed by confocal microscopy, revealing the pattern of "S-phase cells" within the body and enabling a reconstruction of migratory routes of neoblasts to the final location of their differentiated derivatives. In addition the distribution of mitoses can be visualized by fluorescent antiphosphohistone H3 antibodies. Characteristic patterns showed up in different taxonomical groups. In triclad turbellarians (planarians) the BrdU label appeared first in neoblasts and was found later in differentiated cells (Newmark and Sánchez Alvarado 2000). Previous claims that neoblasts were concentrated at the ventral nerve cords (Brøndsted 1969) could not be confirmed; at least there was no incorporation of $\mathrm{BrdU}$ in cells adjacent to these nerves. Instead the label was scattered throughout the parenchyma, with the exception of the pharynx and the region in front of the eyes. Mitoses were found to be located preferentially in two horizontal body planes: one dorsal and one ventral domain. With some rare exceptions, they were absent in front of the eyes.

The patterns of BrdU incorporation in some other taxa could be correlated to the mode of reproduction and the regenerative capabilities. Two representatives of the order Macrostomorpha (Rhabditophora) showed striking differences. In the genus Macrostomum the label was incorporated preferentially in two lateral bands along the nerve cords (Fig. 5), while no cells were pulse-labelled in front of the eyes and few at the rear end (Ladurner et al. 2000). These regions were populated later on by the immigration of labelled cells; the same was observed for posterior regeneration blastemata. This 
genus reproduces sexually and has a rather limited regeneration potential. Similar distribution patterns were found for mitotic cells. Also in Macrostomum BrdU was incorporated only into neoblasts and appeared in differentiated cells later. In the genus Microstomum that has the option between sexual reproduction and transversal fission, no obvious relation of the label to longitudinal nerve cords was observed in animals reproducing asexually. After pulse-labelling, BrdU-positive cells were found throughout the body, in certain species with distinct concentrations in transversal bands flanked by the prospective fission planes (Fig. 6). Similar differences seem to exist in the Acoelomorpha:
Convolutriloba longifissura, a species reproducing sexually and by asexual fissioning (Åkesson et al. 2001), showed no preferences in the location of BrdU labelling in specimens reproducing by fission (Gschwentner et al. 2001) and a uniform distribution of S-phase cells all over the body (Fig. 7). The sexual acoelomorph Convoluta pulchra presented a symmetric pattern of labelled cells along the lateral regions. Still more data will be needed to draw firm conclusions on the relationships between the patterns of proliferating neoblasts, nervous system and mode of reproduction.
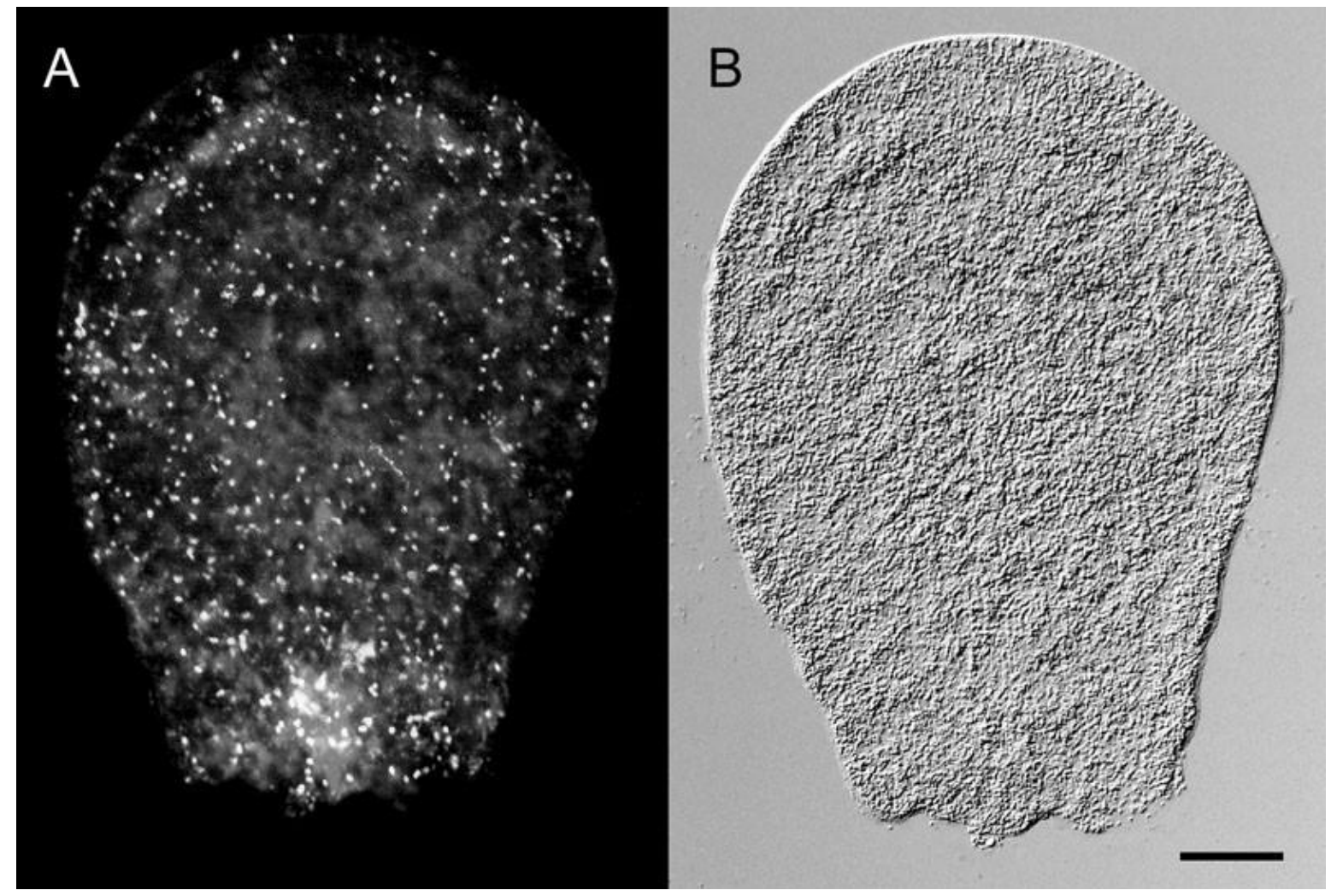

Fig. 7. Distribution of neoblasts in S-phase in Convolutriloba longifissura. Dorsal view of a juvenile animal (anterior end at top). (A) Epifluorescence micrograph with S-phase neoblasts labelled by a 30 min pulse of BrdU and fixed immediately thereafter. Labelled cells, appearing bright, are scattered throughout the body, without any distinct accumulations. (B) Nomarski interference-contrast micrograph of the same animal. Scale bar $200 \mu \mathrm{m}$.

\section{CELL RENEWAL IN FLATWORMS: UNIQUE OR RELATED TO OTHER STRATEGIES IN THE ANIMAL KINGDOM?}

Several years ago, the recruitment of all new cells from a single functional compartment scattered throughout the whole body appeared to be a rather extraordinary strategy for an animal. Within the animal kingdom, the phylum studied best with regard to tissue homeostasis obviously are the vertebrates. The various ways in which mammals maintain their tissues are well known and seem quite different from the turbellarian way of cell renewal. As our knowledge on the potential and plasticity of mammalian somatic stem cells increases (for reviews, see de Haan 2002, Kirchhof et al. 2002 and Vescovi et al. 2002), striking relationships emerge between the capacities of stem cells in mammals and in flatworms. 


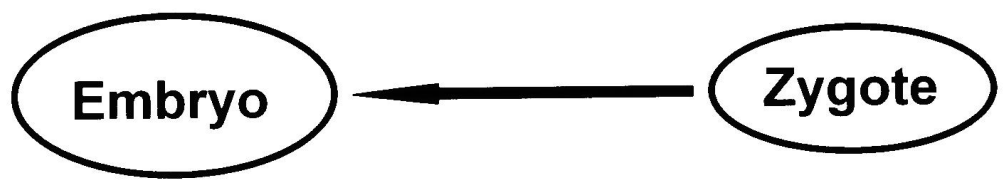

\section{Embryonal stem cells (ESC)}

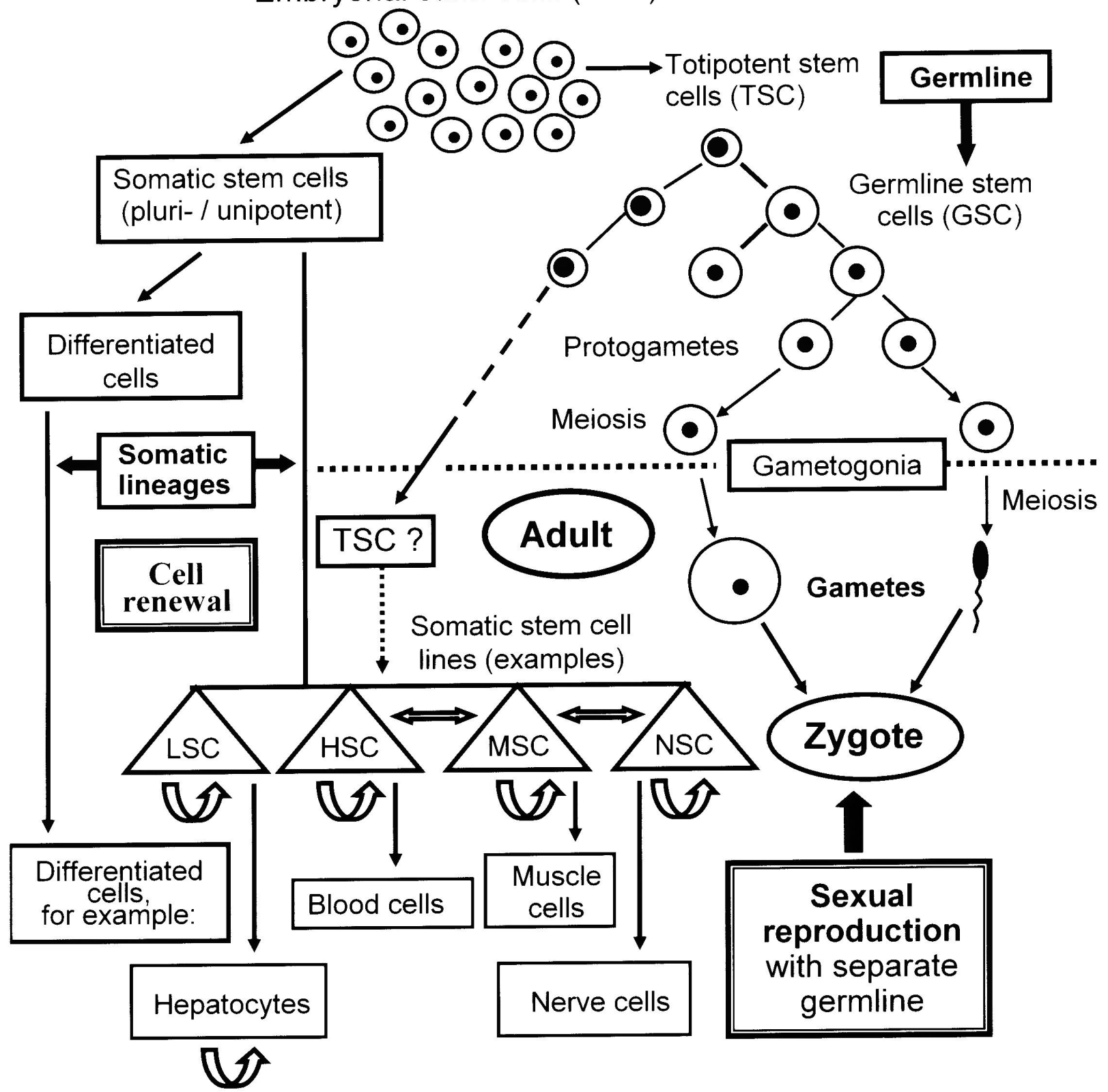

Fig. 8. Cell renewal and reproduction in mammals. A continuous germline connects individuals of successive generations (Weismann 1892). The zygote forms embryonic stem cells (ESC) that give rise to somatic cells and to a separate line of germ cells. Depending on the cell type, somatic tissues in the adult are renewed in different ways: by mitoses of differentiated cells or from stem cells. A great plasticity of stem cells that were, in part, previously unknown, has become evident during the past few years. Even the existence of totipotent stem cells derived from embryonal germline cells and persisting in the adult has been postulated (Weissman 2000). It is still an open issue to what extent specialized (for instance neuronal) stem cells are able to transform to other stem cell types and if some stem cell types only form a rescue team for emergency situations or, in addition, contribute to normal physiological regeneration and growth. Reprinted with permission from Peter (in Cells IV, Kopp Publ., České Budějovice 2002). 

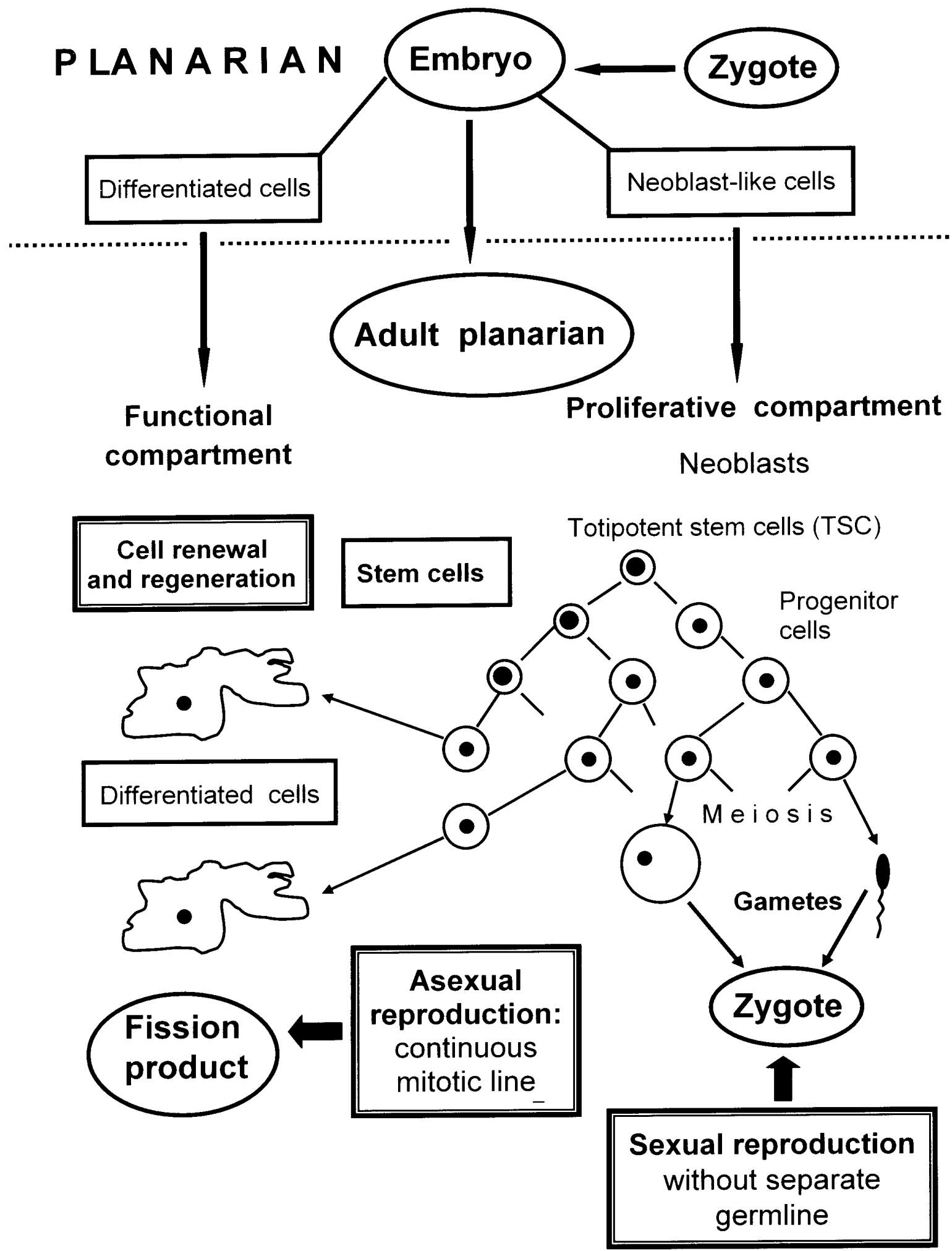

Fig. 9. Cell renewal and reproductive strategies in flatworms, illustrated for planarians (Turbellaria: Tricladida). A stem cell line common for somatic and germ cells and the option between sexual (meiosis and zygote formation in addition to mitoses) and asexual reproduction (based solely on mitoses of stem cel ls) are the characteristic differences to germline strategies (Fig. 8). The individual recruits any cell renewal (including the production of germ cells) from a separate proliferative compartment based on a totipotent stem cell pool. Reprinted with permission from Peter (in Cells IV, Kopp Publ., České Budějovice 2002). 
The main differences between the mammalian and the turbellarian systems of cell renewal (Tab. 1) may be summed up in the following way. Mammals, being organisms with exclusively sexual reproduction, possess one continuous cell lineage transgressing the generations: the germline that has been originally described by Weismann (1892). Mitotic cell generations are connected by meiosis and zygote formation. A connection between germ and somatic cells is only observed during embryogenesis (Fig. 8). Totipotent stem cells derived from embryonic stem cells have been suggested as a link between soma and germ line and to persist as residual cells in small numbers even throughout the adult life (Weissman 2000). There is however no proof for the latter assumption up to now.

In contrast, flatworms reproduce sexually or asexually. These two modes of reproduction may alternate regularly within a life cycle, as for example in trematodes, be an option for one given population or be specific for a strain or species. The latter two cases are observed within the turbellarians. When considering the outlined situation, one single stem cell for both somatic and germ cells makes sense. If every neoblast population really originates from one totipotent stem cell type, there is no barrier between somatic cell lines and germ cells even in the adult (Fig. 9) and one stem cell type supplies the needs for regeneration (physiological and reparative) and reproduction (Peter et al. 2001). There are many indications that this is indeed the case. In purely asexual strains or species (as in Dugesia tahitiensis) a continuous mitotic cell lineage transgresses and connects successive generations.

Unique though it is, the turbellarian stem cell system resembles mammalian stem cells in certain respects (Tab. 1): Also in mammals, somatic stem cells may give rise to tissues that are normally renewed by division of differentiated cells (Fig. 8). It is not yet known to what extent this is only an option for emergency situations and contributes also to physiological tissue regeneration.

Transdifferentiation between different stem cell types has been concluded to occur in mammals in vivo and in vitro. This has been deduced from the fact that stem cells competent for one tissue could regenerate another tissue. There are many examples for this possibility; so skeletal muscle was regenerated by bone marrow stem cells and vice versa (de Haan 2002). Neural stem cells have been shown to form hematopoietic cells in sub-lethally irradiated mice and form many other somatic cells (Vescovi et al. 2002). Hepatocytes were formed from bone marrow cells in mice (Theise, Badve et al. 2000) and in humans (Theise, Nimmakayalu et al. 2000). It has been argued that these transdifferentiations might actually be simulated by a small percentage of residual totipotent stem cells present in the cell suspensions used for the experiments (see above; Weismann 2000). Should this assumption hold true, there would be one more similarity between flatworms and mammals, and the germline might fail to be a consequent barrier in mammals. Such considerations are of course highly speculative, but are favoured by evolutionary arguments. Many assume flatworms to resemble most closely the latest common predecessor of bilaterians among all extant animal taxa. Therefore it seems reasonable supposing the turbellarian stem cell system to be the original and evolutionary old way of cell renewal in bilaterians. Whereas it remained the only possibility for flatworms, higher evolved phyla like the vertebrates acquired additional strategies using differentiated cells or specialized stem cells, but maintained the ancient system mainly for emergency, but also as an additional source for new cells under normal circumstances (see Theise, Badve et al. 2000 and Theise, Nimmakayalu et al. 2000 for hepatocytes). Learning more about neoblasts in turbellarians should enable us to test this hypothesis and should at the same time contribute to a better understanding of stem cells in mammals and humans.

\section{OPEN ISSUES AND OUTLOOK}

It seems to be sure that only neoblasts may divide in turbellarians and therefore are the only source for any cell renewal, including germ cells. They form a totipotent proliferative compartment that persists over generations in asexual turbellarians and is functionally comparable to a germline. Although the existence of a stem cell strategy for growth and tissue homeostasis thus appears to be proven for flatworms, there remain several issues to be clarified. The neoblast compartment is heterogeneous and comprises stem cells, progenitors and early differentiation stages, waiting for a clarification of the mutual relationships. As long as we do not know if there are stem cell subtypes, both possibilities of totipotency must be considered: Either a single cell type or the whole proliferative compartment may be totipotent. In addition, there is no final proof that would rule out alternative ways for the renewal of cells like transdifferentiation and dedifferentiation (cf. Tab. 1). Relationships between true stem cells and progenitors are for the most part obscure. There have been some indications for the transformation of gonadal stem cells into somatic progenitors (Gremigni 1981, commented by Saló and Baguñà 2002), but extensive studies on this 
topic are still missing. The issue of the mutual interrelationships of proliferating cells is closely connected with the question of the ultimate origin of neoblasts. They might descend from neoblastlike cells found early in embryogenesis (Le Moigne 1963), arise at a later stage of development or be renewed from differentiated cells. Should the latter be true, even the stem cell nature of neoblasts that implies a self-renewing pool would have to be questioned. To solve all these open issues, longterm labelling including the embryo will be necessary. Knowledge on the ways in which turbellarian stem cells choose between self-renewal and commitment to progenitor cells (e.g. asymmetric divisions or influence of the microenvironment within the body) and on putative progenitor lineages is still missing completely.

A promising research strategy of subtyping neuronal cells from planarians by cDNA markers in combination with cell sorting (FACS) has recently been reported and will also result in a better understanding of the proliferative compartment of the turbellaria when applied to neoblasts (Asami et al. 2002). Further cell kinetic studies, using labelling with BrdU (Ladurner et al. 2000) in combination with the cytometric analysis of DNA contents and other parameters (Behensky et al. 2001), will add further contributions to the solution of these issues. For Macrostomum sp. molecular markers for stem and germline cells (vasa, piwi, $M C M$, pumilio) are currently being isolated. In situ hybridizations and studies using RNA interference (Sánchez Alvarado and Newmark 1999) will provide new data on the pathways and functions of stem and progenitor cells. One ultimate goal should be a permanent stem cell line that would offer the possibility of conducting differentiation studies in vitro and to introduce genetic markers into stem cells available ad libitum for extensive experiments. Such transgenic cells could then be injected into lethally irradiated hosts in order to trace their fate over long periods of time. Another goal we should ultimately arrive at is of course a precise characterization of proliferating cells by cell surface markers and patterns of gene expression in much the same way as has already been done to a large extent for mammalian haematopoietic cells.

\section{ACKNOWLEDGEMENTS}

The authors would like to thank all colleagues who contributed to this study by technical assistance and stimulating discussions. The experiments performed by the authors and related to this paper were part of a common project supported by the Austrian Science Fund (grants P-13060BIO and
P-15204BIO). This support, the APART scholarship granted to P. L. and the funds given to R. P. by the Sponsoring Society at the University of Salzburg (Stiftungs- und Förderungsgesellschaft) are gratefully acknowledged.

Modified and augmented version of a paper published in J. Berger (ed.): Advances in Cell Biology. Kopp Publ., České Budějovice 2003, pp. 137-156.

\section{REFERENCES}

Åkesson B., R. Gschwentner, J. Hendelberg, P. Ladurner, J. Müller, R. Rieger: Fission in Convolutriloba longifissura: asexual reproduction in acoelous turbellarians, revisited. Acta Zool. 82: 231-239, 2001.

Asami M., T. Nakatsuka, T. Hayashi, K. Kou, H. Kagawa, K. Agata: Cultivation and characterization of planarian neuronal cells isolated by fluorescence activated cell sorting (FACS). Zool. Sci. 19: 1257-1285, 2002.

Auladell C., J. Garcia-Valero, J. Baguñà: Ultrastructural localization of RNA in the chromatoid bodies of undifferentiated cells (neoblasts) in planarians by the RNase-gold complex technique. J. Morph. 216: 319-326, 1993.

Baguñà J.: Planarians. In P. Ferretti and J. Géraudie (eds.): Cellular and Molecular Basis of Regeneration: From Invertebrates to Humans. J. Wiley and Sons, Chichester, New York etc., 1998, pp. 135-165.

Baguñà J., E. Saló, C. Auladell: Regeneration and pattern formation in planaria. III. Evidence that neoblasts are totipotent cells and the source of blastema cells. Development 107: 77-86, 1989.

Baguñà J., E. Saló, R. Romero, J. GarcíaFernàndez, D. Bueno, A.M. Muñoz-Marmol, J.R. Bayascas-Ramirez, A. Casali: Regeneration and pattern formation in planarians: cells, molecules and genes. Zool. Sci. 11: 781-795, 1994.

Behensky C., W. Schürmann, R. Peter: Quantitative analysis of turbellarian cell suspensions by fluorescent staining with acridine orange, and video microscopy. Belg. J. Zool. 131 (Supplement 1): 131-136, 2001.

Betchaku T.: Isolation of planarian neoblasts and their behavior in vitro with some aspects of the mechanism of the formation of regeneration blastema. J. Exp. Zool. 164: 407-434, 1967.

Brøndsted H.V.: Planarian Regeneration. Pergamon Press, Oxford/London etc., 1969, pp. vii+276. 
Buchner E. and R. Peter: Influences of ionizing radiation on regeneration and neoblasts (stem cells) in the planarian Dugesia tahitiensis (Turbellaria: Tricladida Paludicola). In J. Berger (ed.): Cells IV. Kopp Publ., České Budějovice 2002, p. 116.

de Haan G.: Hematopoietic stem cells: selfrenewing or aging? Cells Tissues Organs 171: 27-37, 2002

Ehlers U.: The Phylogenetic System of the Platyhelminthes (In German). G. Fischer, Stuttgart, 1985, pp. 317.

Gremigni V.: The problem of cell totipotency, dedifferentiation and transdifferentiation in Turbellaria. Hydrobiologia 84: 171-179, 1981.

Gremigni V.: Planarian regeneration: an overview of some cellular mechanisms. Zool. Sci. 5: 1153-1163, 1988.

Gschwentner R., P. Ladurner, K. Nimeth, R. Rieger: Number and distribution of S-phase and mitotic cells in Convolutriloba longifissura (Platyhelminthes: Acoela). Cell Tissue Res. 304: 401-408, 2001.

Gustafsson M.K.S.: The cells of a cestode. In M.K.S. Gustafsson and M. Reuter (eds.): The early brain. Åbo Academy Press, Åbo 1990: pp. 13-44.

Keller J.: The asexual reproduction of the freshwater turbellarians (In German). Jen. Zeitschr. Naturwissensch. 28: 370-407, 1894.

Kirchhof N., F. Harder, S. Petrovic, S. Kreutzfeldt, C. Schmittwolf, M. Dürr, J. Kirsten, B. Mühl, A. Merkel, A.M. Müller: Developmental potential of hematopoietic and neural stem cells: unique or all the same? Cells Tissues Organs 171: 77-89, 2002.

Ladurner P., D. Reiter, D. Riedl, R.M. Rieger: Stem cells in turbellarian development, growth and regeneration. Dev. Biol. 198: 209, 1998.

Ladurner P., R. Rieger, J. Baguñà: Spatial distribution and differentiation potential of stem cells in hatchlings and adults in the marine platyhelminth Macrostomum sp.: a bromodeoxyuridine analysis. Dev. Biol. 226: 231-241, 2000.

Le Moigne A.: Study of the embryonic development of Polycelis nigra (triclad turbellarian) (In French). Bull. Soc. Zool. Fr. 88: 403-422, 1963.

Loeffler M. and I. Roeder: Tissue stem cells: definition, plasticity, heterogeneity, selforganization and models - a conceptual approach. Cells Tissues Organs 171: 8-26, 2002.

Morita M. and J.B. Best: Electron microscopic studies of planarian regeneration. IV. Cell division of neoblasts in Dugesia dorotocephala. J. Exp. Zool. 229: 425-436, 1984.
Morrison S.J., N.M. Shah, D.J. Anderson: Regulatory mechanisms in stem cell biology. Cell 88: 287-298, 1997.

Newmark P.A. and A. Sánchez Alvarado: Bromodeoxyuridine specifically labels the regenerative stem cells of planarians. Dev. Biol. 220: 142-155, 2000.

Palmberg I.: Stem cells in microturbellarians. An autoradiographic and immunocytochemical study. Protoplasma 158: 109-120, 1990.

Pedersen K.J.: Morphogenetic activities during planarian regeneration as influenced by trimethylene melamine. J. Embryol. Exp. Morphol. 6: 308-334, 1958.

Pedersen K.J.: Cytological studies on planarian neoblasts. Z. Zellforsch. 50: 799-817, 1959.

Peter R.: Experimental systems for studying regeneration processes: Turbellarians as model organisms with a stem cell system (In German). Ber. nat.-med. Verein Innsbruck 88: 287-350, 2001.

Peter R.: A totipotent proliferative compartment: the unique stem cell strategy of flatworms. In J. Berger (ed.): Cells IV. Kopp Publ., České Budějovice 2002, pp. 31-40.

Peter R., P. Ladurner, R.M. Rieger: The role of stem cell strategies in coping with environmental stress and choosing between alternative reproductive modes: Turbellaria rely on a single cell type to maintain individual life and propagate species. Marine Ecology 22: 3551, 2001.

Rieger R.M., A. Legniti, P. Ladurner, D. Reiter, E. Asch, W. Salvenmoser, W. Schürmann, R. Peter: Ultrastructure of neoblasts in microturbellaria: significance for understanding stem cells in free-living Platyhelminthes. Invertebr. Reprod. Dev. 35: 127-140, 1999.

Saló E. and J. Baguñà: Regeneration and pattern formation in planarians. I. The pattern of mitosis in anterior and posterior regeneration in Dugesia (G) tigrina, and a new proposal for blastema formation. J. Embryol. Exp. Morphol. 83: 6380, 1984.

Saló E. and J. Baguñà: Regeneration in planarians and other worms: new findings, new tools and new perspectives. J. Exp. Zool. 292: 528-539, 2002.

Sánchez Alvarado A.S. and P.A. Newmark: Double stranded RNA disrupts gene expression during planarian regeneration. Proc. Natl. Acad. Sci. USA 96: 5049-5054, 1999.

Sauzin-Monnot M.J.: Ultrastructural study of the neoblasts of Dendrocoelum lacteum during regeneration (In French). J. Ultrastruct. Res. 45: 206-222, 1973.

Schürmann W. and R. Peter: Planarian cell culture: a comparative review of methods and an 
improved protocol for primary cultures of neoblasts. Belg. J. Zool. 131 (Suppl. 1): 123130, 2001.

Schürmann W. and R. Peter: Primary cultures of neoblasts (stem cells) from the planarians Dugesia tahitiensis and Schmidtea polychroa (Platyhelminthes: Turbellaria Tricladida). J. appl. Biomed. 1 (Suppl. 1): S2829, 2003.

Schürmann W., S. Betz, R. Peter: Separation and subtyping of planarian neoblasts by densitygradient centrifugation and staining. Hydrobiologia 383: 117-124, 1998.

Shibata N., Y. Umesono, H. Orii, T. Sakurai, K. Watanabe, K. Agata: Expression of vasa(vas)-related genes in germline cells and totipotent somatic stem cells of vasa planarians. Dev. Biol. 206: 73-87, 1999.

Theise N.D., S. Badve, R. Saxena, O. Henegariu, S. Sell, J.M. Crawford, D.S. Krause: Derivation of hepatocytes from bone marrow cells in mice after radiation-induced myeloablation. Hepatology 31: 235-240, 2000.

Theise N.D., M. Nimmakayalu, R. Gardner, P.B. Illei, G. Morgan, L. Teperman, O. Henegariu, D.S. Krause: Liver from bone marrow in humans. Hepatology 32: 11-16, 2000.

Vescovi A., A. Gritti, G. Cossu, R. Galli: Neural stem cells: plasticity and their transdifferentiation potential. Cells Tissues Organs 171: 64-76, 2002.

Weismann A.: The germ plasm. A theory of heredity (In German). Fischer, Jena 1892.

Weissman I.L.: Stem cells: units of development, units of regeneration, and units in evolution. Cell 100: 157-168, 2000.

Wikgren B.-J. and C.M. Knuts: Growth of subtegumental tissue in cestodes by cell migration. Acta Acad. Aboensis Ser. B 30: 1-6, 1970.

\section{Address:}

Roland Peter, Department of Genetics and General Biology, University of Salzburg, Hellbrunnerstr. 34, A-5020 Salzburg, Austria; Roland.Peter@sbg.ac.at 